\title{
Computational Fluid Dynamics Applied to Atherosclerosis Hemodynamics: A Brief Review
}

\author{
Fernanda Sodré*; Alex Álisson Bandeira Santos; Luzia A. Tofaneli; Turan D. Oliveira \\ SENAI CIMATEC, Laboratório de Energia, Salvador, Bahia, Brazil
}

\begin{abstract}
In recent years, Computational Fluid Dynamics (CFD) has been applied to biological systems for the study of physiological properties and the development of new medical devices. It has also been used for the hemodynamic evaluation of care in the diagnosis, treatment, and prevention of cardiovascular diseases. This article presents a brief analysis of the application of Computational Fluid Dynamics in hemodynamics in atherosclerosis, with a review of CFD in the study of blood flow, and in the medical area.
\end{abstract}

Keywords: Computational Fluid Dynamics. Hemodynamics. Atherosclerosis.

Computational Fluid Dynamics (CFD) is a set of numerical methods that obtain solutions to problems involving physical and chemical phenomena of fluid dynamics and heat transfer [1].

CFD has applied only in high technology engineering a few decades ago [2]. However, its use has now expanded to other applications, such as petrochemicals, automotive, aerospace, and medical industries.

The medical field has shown increasing interest in computer simulations because of the ability to reproduce the effects that influence medical diagnoses [3]. There are many advantages of using CFD in the area of health. It is a non-invasive method for research in biological systems, reducing the risks involved in a procedure. Also, it is faster and involves lower costs when compared to experimental and theoretical methods [4,5].

Computational Fluid Dynamics has been applied in different fields of research in several medical areas. Augusto (2014) [6] studied air flow and particle deposition in the pulmonary airways using CFD (Figure 1). Similarly, Kim and colleagues (2013) [7] used the method to simulate airflow inside the nasal cavity.

Received on 18 February 2019; revised 24 February 2019. Address for correspondence: Dr. Fernanda Sodré. Avenida Centro Universitário SENAI CIMATEC; Av. Orlando Gomes, 1845 - Piatã, Zip code: 41.650-010; Salvador, Bahia, Brazil. E-mail: nandacsodre@gmail.

J Bioeng. Biotech. Appl. Health 2019;2(1):15-20.

(C) 2019 by SENAI CIMATEC. All rights reserved.
Figure 1. Velocity areas in the time of air inspiration in the trachea.

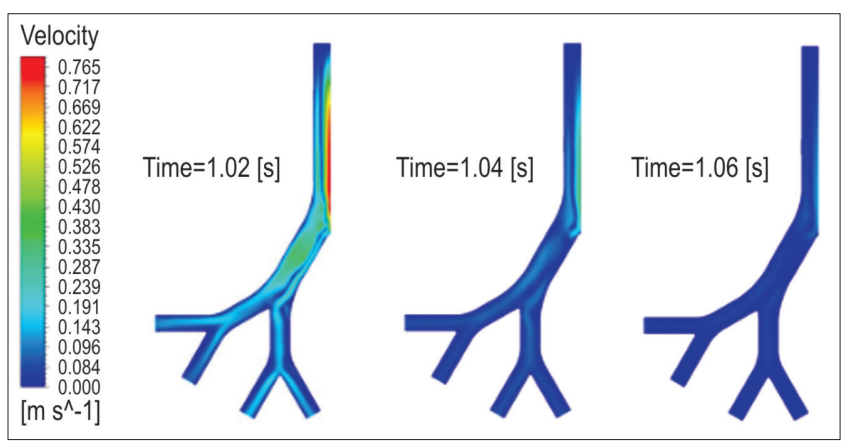

Source: Augusto 2014 [6].

CFD has also been used for the development of medical devices and endoprosthesis. Feurhuberand colleagues [8] used the statistical approach of CFD for steam sterilization tests. The results concluded that the model developed by CFD can predict properties, such as temperature, steam quality; and also the visualization and understanding of the sterilization procedure.

Another significant area is the computational analysis of blood flow. The application of CFD in hemodynamics has featured in several studies, especially those related to cardiovascular diseases, such as atherosclerosis and aneurysms.

Lima and colleagues (2015) [5] and Blessy and colleagues (2016) [9] presented studies that reviewed the application of numerical methods and computational simulations in hemodynamics. The present work aims to demonstrate the relevance of CFD applied to hemodynamics in atherosclerosis through a brief literature review. 


\section{Computational Fluid Dynamics}

Fluid dynamics is based in Navier-Stokes equations, which is conduct by the mass conservation and momentum (Equations - (1) (3)].

$$
\begin{aligned}
& \frac{\partial(\rho u)}{\partial t}+\operatorname{div}(\rho u \vec{u})=-\frac{\partial p}{\partial x}+\operatorname{div}(\mu \quad \operatorname{grad} \quad u)+S_{M x}(1) \\
& \frac{\partial(\rho v)}{\partial t}+\operatorname{div}(\rho v \vec{u})=-\frac{\partial p}{\partial y}+\operatorname{div}\left(\begin{array}{lll}
\mu & \operatorname{grad} & v)+S_{M y}(2)
\end{array}\right. \\
& \frac{\partial(\rho w)}{\partial t}+\operatorname{div}(\rho w \vec{u})=-\frac{\partial p}{\partial z}+\operatorname{div}(\mu \quad \operatorname{grad} \quad w)+S_{M z}
\end{aligned}
$$

$\mathrm{p}=$ pressure $\mathrm{t}=$ time $; \mathrm{x}, \mathrm{y}, \mathrm{z}=$ Cartesian directions; $\mathrm{u}, \mathrm{v}$ and $\mathrm{w}=$ velocities in $\mathrm{x}, \mathrm{y}, \mathrm{z}$ directions (three-dimensional velocity vector); $\mu=$ viscosity of the fluid; $\mathrm{S}_{\mathrm{MX}}, \mathrm{S}_{\mathrm{MY}}, \mathrm{S}_{\mathrm{MZ}}=$ transitory terms in the directions described.

The difficulty in solving the conservation equations analytically for turbulent flow and complex geometry applications requires the application of numerical solutions.

There are 3 different streams of numerical solutions techniques: finite difference, finite element, and spectral methods. The method of finite volume method is central to the most well-established codes, such as CFX/ANSYS, FLUENT, PHOENICS and STAR-CD [10].

Despite using numerical models, the approach of the turbulence phenomena requires the application of turbulence models to reduce computational time. References and theoretic indications frequently used turbulence models (Table 1).

\section{The Use of CFD in Hemodynamics}

Hemodynamics is the study of blood circulation through blood vessels, arteries, veins and capillaries that make up the cardiovascular system [11]. Mathematical models proposed by CFD can simulate the cardiovascular system [12]. The study of CFD in hemodynamics can help to understand what occurs during blood flow. As a result, it could aid in the diagnosis and prevention

\begin{tabular}{|c|c|}
\hline Model & Brief description and equations \\
\hline $\mathrm{k}-\varepsilon$ & $\begin{array}{l}\qquad k=\frac{3}{2}\left[I_{\text {def }} \max \left(U_{s},\left|U_{I G}\right|, U_{\omega}\right)\right]_{(4)}^{2} \\
\qquad \varepsilon=\frac{C_{\mu} k^{2}}{v \cdot\left(\mu_{T} / \mu\right)} \\
\text { This model focuses on the } \\
\text { parameters that affect the } \\
\text { turbulence kinetic energy. It is good } \\
\text { to converge. }\end{array}$ \\
\hline $\mathrm{k}-\omega$ & $\begin{array}{l}\qquad k=\frac{3}{2}\left[I_{\text {def }} \max \left(U_{s},\left|U_{I G}\right|, U_{\omega}\right)\right]^{2} \\
\qquad \omega=\frac{k}{v \cdot\left(\mu_{T} / \mu\right)}(6) \\
\text { Similar to k-E, but this model has } \\
\text { improved accuracy for internal } \\
\text { flows, and separated flows. } \\
\text { However, this model is hard to } \\
\text { converge, despite more expensive. }\end{array}$ \\
\hline $\mathrm{k}-\omega \mathrm{SST}$ & $\begin{array}{l}\text { Combination of } \mathrm{k}-\varepsilon \text { and } \mathrm{k}-\omega \text {. This } \\
\text { model is difficult to converge. }\end{array}$ \\
\hline
\end{tabular}
of cardiovascular diseases; the identification of
Table 1. Models of turbulence.

hemodynamic properties; the analysis of advanced diseases; surgical procedure and the development of medical devices.

The application ofCFD is based on the following 7 steps: clinical imaging, segmentation and reconstruction, discretization, contour conditions, simulation, post-processing and validation [13].

Medical images provide anatomical and physiological details, which are obtained from ultrasound, computed tomography and magnetic resonance imaging [13]. The conversion of clinical images into geometric models is the base of the segmentation and reconstruction' stages.

Discretization is the production and refinement of the computationalmesh that divides the geometry into volumetric cells. The limit conditions are the physical conditions for the entry, exit, and walls of the model, and the initial parameters and properties of the fluids used.

Computer simulation of cardiovascular system in $3 \mathrm{D}$ consumes time and computational demand. Post-processing is done, such as graphs and tables for analysis, to extract the relevant data. After that, 
the results obtained are analyzed and compared with existing parameters in medicine for validation [13].

An important hemodynamic factor is the viscosity of blood flow. The blood's viscosity can vary according to the applied shear stress. If the strain rate is higher than $100 \mathrm{~s}-1$, which happens in the large arteries, the blood behaves as a Newtonian fluid (constant viscosity). However, if the rate is lower than $100 \mathrm{~s}-1$, the viscosity will present nonNewtonian behavior (variable viscosity) which occurs in the small arteries $[14,15]$.

There are some models for representing the non-Newtonian behavior of blood flow, such as the Casson model, the Carreau model and the Power Law model [12]. A comparison of the viscosity of these models is shown in Figure 2 [12].

Figure 2. Comparison between the viscosity of the Newtonian and non-Newtonian models.

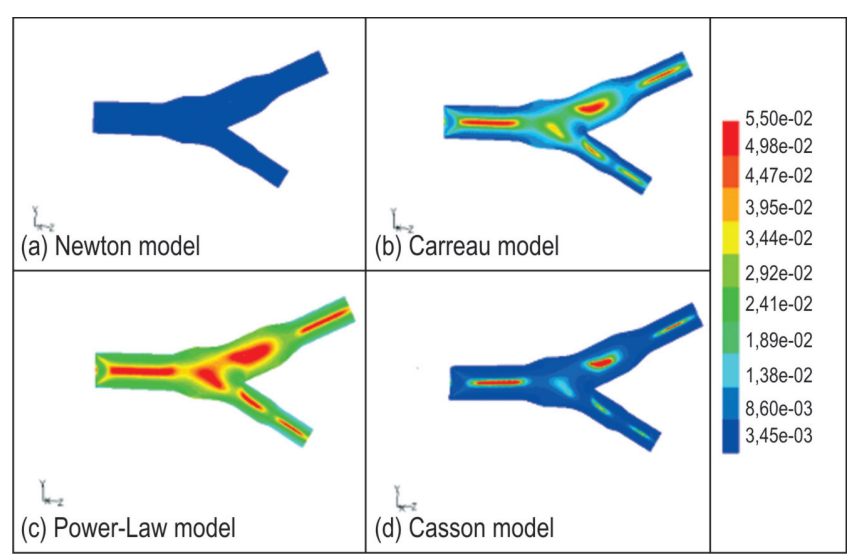

Source: Brambatti (2010) [12].

Tabacow (2014) [16] used CFD in a study of cardiovascular diseases, in which the influence of endoprosthesis on aneurysms through a computational analysis of circulation of blood was analyzed. This result was able to justify the implantation of an endoprosthesis in patients to reduce the degradation of the vessel.

Azevedo (2010) [17], as well as Shishir and colleagues (2015), studied hemodynamic properties in models of saccular aneurysms to understand the pathology (Figure 3).
Figure 3.Types of saccular aneurysms.

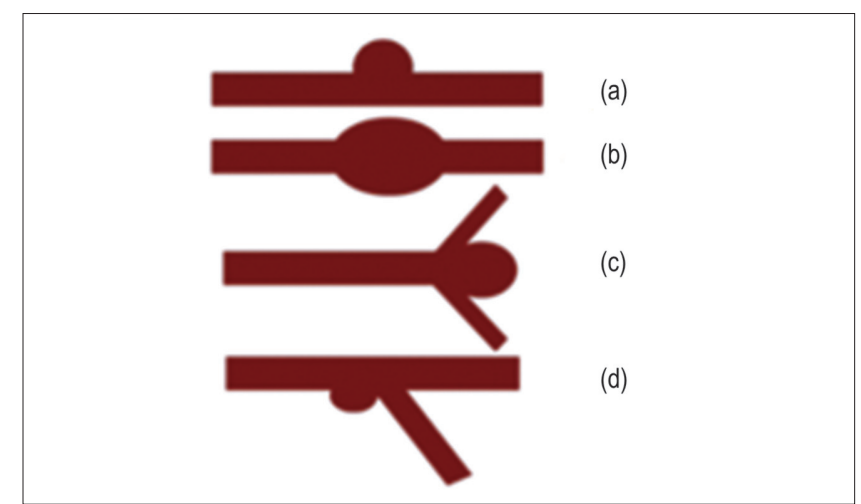

(a) lateral aneurysm; (b) fusiform aneurysm; (c)terminal aneurysm; (d) aneurysm in a bifurcation.

Source: Adapted from Azevedo (2010) [17].

\section{The Use of CFD in Atherosclerosis}

Heart disease is the leading cause of death in the world [19], and atherosclerosis will become the primary source of this disease by 2020 [20].

Atherosclerosis is the result of the deposition and accumulation of fatty-rich and inflammatory substances that accumulate on vessels walls and form atherosclerotic plaques. These events limit the blood flow, causing a narrowing and hardening of the vessels, causing an inadequate supply to vital organs (Figure 4) [21-23].

Atherosclerosis affects regions of complex hemodynamics, such as arterial bifurcations, usually in areas of low shear stress [24]. The shear stress in the vessel walls is one of several

Figure 4. Representation of atherosclerotic plaques on artery walls.

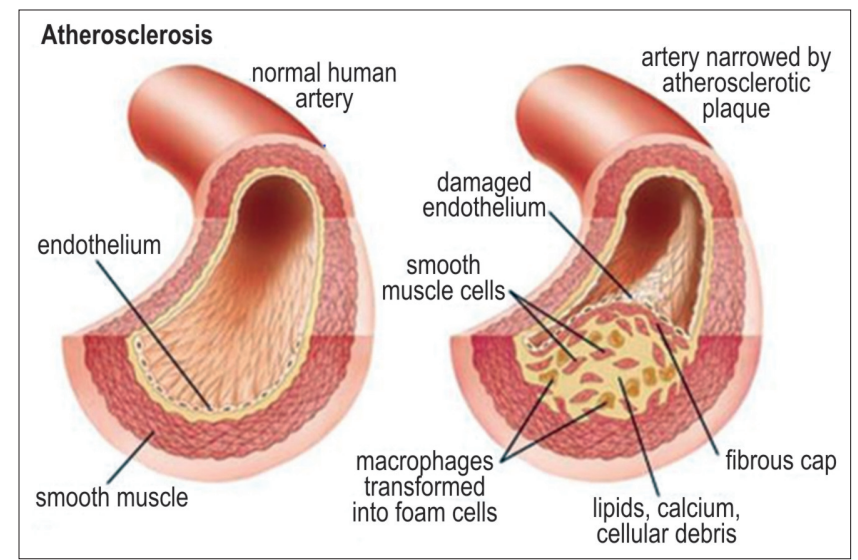

Source: Henriques (2015) [23]. 
hemodynamic factors that are related to the development of the disease [25]. Therefore the identification of these factors could enable early detection and prevention of atherosclerosis [26], as well as help in assessing the severity of stenosis [23].

Computational simulations of atherosclerosis can help in the determination and analysis of these factors, collaborating with the treatment and prevention of the disease. Figure 5 shows the shear stress in the artery with atherosclerosis, showing a tension peak in the existing damage point.

The CFD method has contributed to the therapeutic and surgical planning of the most various cardiovascular diseases [27]. It could also collaborate in the surgical procedures by predicting the results of stenosis. The study developed by Polanzyck and colleagues (2018) [28] is a comparison of before and after surgeries of stenosis through computational simulations and medical examinations. It was possible to use CFD to assist in predicting the outcome of critical stenosis surgeries with a 90\%-98\% accuracy in results [28].

Furthermore, several studies are using CFD for medical devices that aid in the treatment and procedure of atherosclerosis [29-32]. Figure 6 shows the results of the variation in shear stress with a stent implanted in the artery. There has also been research into the development of equipment, such as the analysis developed by Dehlahi and colleagues (2008) [33], which compares the properties of different stent models.

\section{Future Perspectives}

According to Lima and colleagues [5], the implementation of computational methods combined with conventional methods will enable the development of predictive medicine, such as the choice of appropriate surgery based on the comparison between results of computational surgeries performed. Furthermore, the mapping of the physiological properties of atherosclerosis hemodynamics should be done for prevention
Figure 5. Representation of shear stress in a simulation of atherosclerosis.

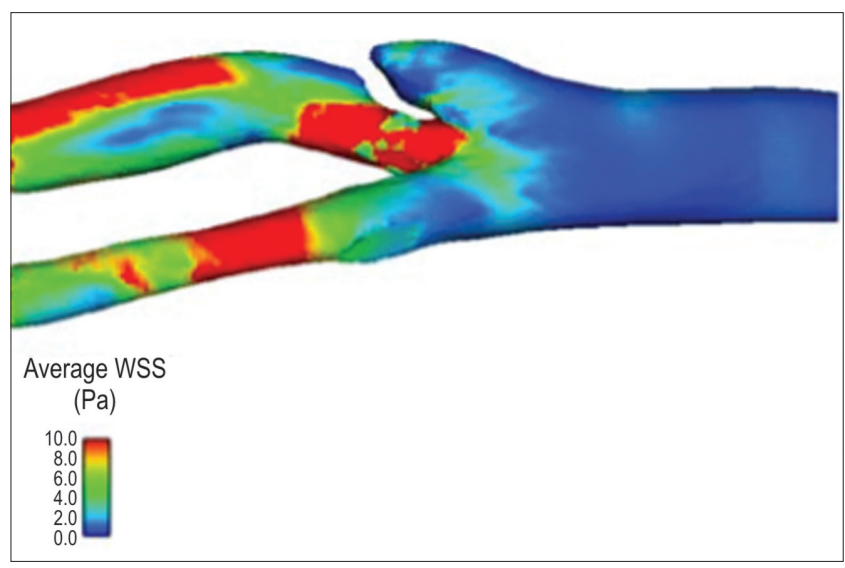

Source: Birchall (2006) [24].

Figure 6. Results of shear stress in simulations of blood models with a stent.

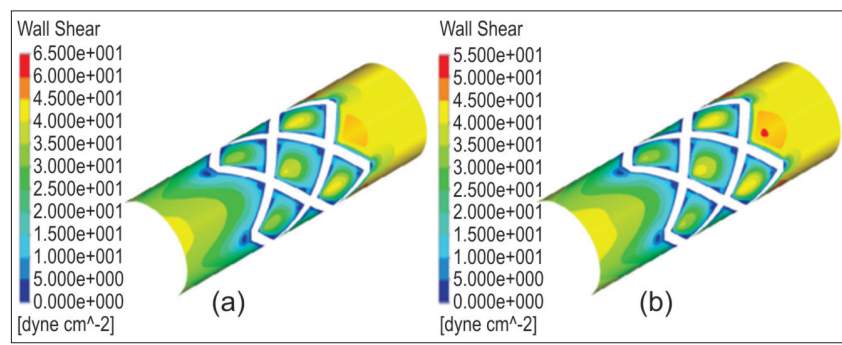

Source:Hsiao(2012) [31].

and diagnosis, as well as the development of technologies and devices for treatments and procedures in the disease.

\section{Conclusions}

Computational Fluid Dynamics can contribute to advances in medicine, especially in the study and analysis of hemodynamics applied to cardiovascular diseases.

However, more studies are needed with CFD applied to medicine to apply this method for other diseases, using new fields of Engineering in Medicine.

\section{Acknowledgments}

SENAI CIMATEC University Center and FAPESB (Foundation for Research Support of the State of 
Bahia) for their financial and technological support in the development of this study.

\section{References}

1. Zikanov, O. Essential Computacional Fluid Dynamics. New Jersey: 2010.

2. Carneiro, A.F.G. C. Influência do Ciclo Cardíaco no Fluxo Sanguíneo na Vizinhaça da Bifurcação Ilíaca.2009. Doctoral thesis in mechanical engineering - University of Minho; 2009.

3. Malecha, Z. et. al. GPU-based simulation of 3D blood flow in abdominal aorta using OpenFOAM. Arch. Mech. 2011;63:137-61. Warszawa - Polônia.

4. Carvalho, J.B. Estudo numérico hemodinâmico de um aneurisma na vizinhança de uma bifurcação arterial tridimensional. Masters dissertation for mechanicalengineering - Universidade Estadual Paulista (UNESP); 2017.

5. Lima, R., Tsubota, K., Wada, S., Yamaguchi, T. Os Métodos Computacionais em Hemodinâmica. ResearchGate. 2015.

6. Augusto, L.L.X. Aplicação da Fluidodinâmica Computacional (CFD) no estudo do escoamento de ar e deposição de partículas em vías aéreas pulmonares. 2014. Masters dissertation for chemical engineering Universidade Federal de São Carlos; 2014.

7. Kim, S.K., Na, Y., Kim, J., Chung, S. Patient specific CFD models of nasal airflow: Overview of methods and challenges. Journal of Biomechanics. 2013;46:229-306.

8. Feurhuber, M., Cattide, A., Magno, M., et al. Prediction of the fluid flow, heat transfer and inactivation of microorganism at medical devices in modern steam sterilizers using computational fluid dynamics. Applied Thermal Engineering. 2017;127:1391-403.

9. Blessy, T., Sumam, K.S. Blood flow in human arterial system-a review. Procedia Technology. 2016;24:339-46.

10. Versteeg, H.K., Malalasekera, W. An Introduction to Computational Fluid Dynamics: The Finite Volume Method. Second edition. Edinburgh Gate: Pearson. 2007.

11. Alves, L.V.S. Otimização da geometria da prótese arterial para intervenção cirúrgica. Porto: Faculdade de Engenharia da Universidade do Porto, 2013.

12. Brambatti, V.M. Utilização da técnica de CFD para simulação do escoamento de sangue em artéria humana. Doctoral thesis in Aerodynamics, Propulsionand Energy - Instituto Tecnológico de Aeronáutica, São José dos Campos; 2010.

13. Morris, P.D., Narracott, A., Tengg-Kobligk, H.V., et al. Computational fluid dynamics modelling in cardiovascular medicine. Heart. 2016;102:18-28.

14. Rabby, M.G., Razzak, A., Molla, Md.M. Pulsatile non-Newtonian blood flow through a model of arterial stenosis. Procedia Technology. 2013;56:225-31.
15. Akbar, N.S., Nadeem, S. Carreau fluid model for blood flow through a tapered artery with a stenosis. Ain Shams Engineering Journal. 2014;5:1307-16.

16. Tabacow, F.B.D. Análise computacional de esforços hemodinâmicos em aneurisma de aorta abdominal infrarenal antes e após a instalação de endopróteses. Masters dissertation for mechanical engineering - Universidade São Paulo (USP); 2014.

17. Azevedo, B.M.C. Estudo preliminar da hemodinâmica em modelos simplificados de aneurismas saculares. Masters dissertation for mechanical engineering - Faculdade de Engenharia da Universidade do Porto; 2010.

18. Shishir, S.S., Miah, Md.A.K., et al. Blood Flow Dynamics in Cerebral Aneurysm - A CFD Simulation. Procedia Engineering. 2015;105:919-27.

19. Roy, M., Sikarwar, B.S., Bhandwal, M., Ranjan, P. Modelling of blood flow in stenosed arteries. Procedia Computer Science. 2017;115:821-30.

20. Fauci, A.S., Braunwald, E., Kasper, D., et. al. Harrison's principles of internal medicine. 2008. 17.a ed. NewYork: McGrawHill.

21. Silva, H.J.G. Caracterização do fluxo sanguíneo duma Bifurcação da Artéria Carótida com Estenose. Masters dissertation for mechanical engineering - Faculdade de Engenharia da Universidade do Porto; 2015.

22. Kumar, S., Deoghare, A.B. Modelling of Human Abdominal Artery for Blood flow Analysis. Materials Today: Proceedings. 2018;5:12877-85.

23. Henriques, H.A.M. Caracterização do fluxo sanguíneo de uma bifurcação da artéria carótida comum com estenose. Masters dissertation for Biomedical engineering Universidade do Porto; 2015.

24. Birchall, D., Zaman, A., Hacker, J., Davies, G., Mendelow, D. Analysis of haemodynamic disturbance in the atherosclerotic carotid artery using computational fluid dynamics. EurRadiol. 2006;16:1074-83.

25. Chen, J., Lu, X. Numerical investigation of the nonNewtonian pulsatile blood flow in a bifurcation model with a non-planar branch. Journal of Biomechanics. 2006;39:818-32.

26. Chaichana, T., Sun, Z., Jewkes, J. Computation of hemodynamics in the left coronary artery with variable angulations.Journal of Biomechanics. 2011;44:1869-78.

27. Feijó, R. Projeto de pesquisa e desenvolvimento do LNCC/MCT em modelagem e simulação computacional do sistema cardiovascular humano. Laboratório Nacional de Computação Científica (LNCC). Petrópolis - 2004.

28. Polanzyck, A., Podgorski, M., Wozniak, T., Stefanczk, L., Strzelecki, M. Computational fluid dynamics as an engineering tool for the reconstruction of hemodynamics after carotid artery stenosis operation: a case study. Medicina. 2018;54(42).

29. Contim, M., Long, C., Marconi, M., et al. Carotid artery hemodynamics before and after stenting: A patient specific CFD study. Computers \& Fluids. 2016;141:62-74. 
30. Santos, G.B. Hemodynamic changes in intracranial aneurysms due to stent-induced vascular remodeling. Masters dissertation for mechanical engineering - Universidade Estadual Paulista; 2018.

31. Hsiao, H., Lee, K., Liao, Y., Cheng, Y. Hemodynamic simulation of intra-stent blood flow. Procedia Engineering. 2012;36:128-36.
32. Dehlahi, V., Tafazoli, S., Najarian, S. Analysis of wall shear stress in stented coronary artery using 3D computational fluid dynamics modeling. Journal of materials processing technology. 2008;197:174.

33. Li, Y., Zhang, M., Verrelli, D.I., et al. Numerical simulation of aneurysmal haemodynamics with calibrated porous-medium models of flow-diverting stents. Journal of Biomechanics. 2018;80:88-94. 